\title{
Monitoring of Dead Sea water surface variation using multi-temporal satellite data and GIS.
}

\begin{abstract}
Remote sensing (RS) and geographic information systems (GIS) are very useful for environmental-related studies, particularly in the field of surface water studies such as monitoring of lakes. The Dead Sea is exposed to very high evaporating process with considerable scarcity of water sources, thus leading to a remarkable shrinkage in its water surface area. The lake suffers from dry out due to the negative balance of water cycle during the previous four decades. This paper discusses the application of RS, GIS, and Global Positioning System to estimate the lowering and the shrinkage of Dead Sea water surface over the period 1810-2005. A set of multi-temporal remote sensing images were collected and processed to show the lakes aerial extend shrinkage from 1973 up to 2004. Remote sensing data were used to extract spatial information and to compute the surface areas for Dead Sea for various years. The current study aims at estimating the fluctuation of Dead Sea level over the study period with special emphasis on the environmental impact assessment that includes the degradation level of the Dead Sea. The results indicated that there is a decrease of $20 \mathrm{~m}$ in the level of the Dead Sea that has occurred during the study period. Further, the results showed that the water surface area of the Dead Sea has shrunk from $934.26 \mathrm{~km} 2$ in 1973 to $640.62 \mathrm{~km} 2$ in 2004.
\end{abstract}

Keyword: Remote sensing, Geographic information system (GIS), GPS, Dead Sea, Water shrinkage, Jordan 